\title{
66. The Effect of Uranium Radiation on the Silk-worms, Bombyx mori $L$.
}

\author{
By Arata Terao and Naoki Wakamori. \\ Imperial Fisheries Institute, Fukagana, Tokyo.
}

(Rec. March 26, 1926. Comm. by Chiyomatsu Ismrawa, M.I.A. April 12, 1926.)

The experimelits recorded in the present paper were carried at the 'Tokyo Sericultural College to ascertain whether or not a certain dose of uranium radiation accelerates the development of the silk-worms. Before proceeding any further, we must return our liearty thanks to Dr. I. Honda, Director of the Sericultural College for the fucilities kindly extended to us.

Experiment I.-A batch of about $400 \mathrm{cggs}$ was divided into four groups, viz., A) control, B) irraliated with uranium during freezing period, C) irradiated during freczing and incubating periods, and D) irradiated during freezing period and subsequent sojourn at room temperature. Two grams of uranium oxide was enveloped within thin paper, immersed in melted soft paraffin, and cooled. A board thus obtained was obliquely put at the bottom of three vials and the groups B, C, and D were closely placed on each board. A lead sheath of $2.5 \mathrm{~mm}$. in thickness was used to prevent the radiation from reaching the control.

Throughout the whole larval life the group $\mathrm{C}$ excelled the others in vigor, and several individuals of this group developed earlier than any of the other three. Other features may be tabulated as follows:- 
No. 4.] The Effect of Uranium Radiation on the Silk-worms, Bombyx mori L.

\begin{tabular}{|c|c|c|c|c|c|}
\hline \multicolumn{2}{|c|}{ Group } & A & B & $\mathrm{C}$ & $\mathrm{D}$ \\
\hline \multicolumn{2}{|c|}{ Hatching } & May 10,11 a.m. & Do. & Do. & May 16,4 p.m. \\
\hline \multicolumn{2}{|c|}{ Mounting } & June 9, 11 p.m. & Do. & Do. & June 15,2 p.m. \\
\hline \multirow{4}{*}{ 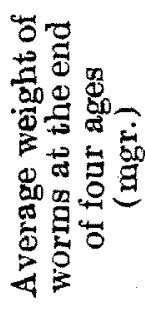 } & 1st age & 5.00 & 4.90 & 5.00 & 5.60 \\
\hline & 2nd age & 29.50 & 31.00 & 31.50 & 32.50 \\
\hline & 3rd age & 168.10 & 167.10 & 175.10 & 178.10 \\
\hline & 4th age & 782.50 & 782.50 & 806.28 & 750.00 \\
\hline \multirow{4}{*}{  } & silk & 0.206 & 0.228 & 0.212 & 0.234 \\
\hline & pupa & 1.425 & 1.364 & 1.523 & 1.500 \\
\hline & exuvia & 0.075 & 0.0797 & 0.0844 & 0.0750 \\
\hline & total & 1.706 & 1.6717 & 1.8194 & 1.809 \\
\hline \multirow{2}{*}{ 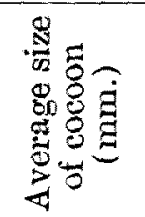 } & length & 33.03 & 33.39 & 35.67 & 32.73 \\
\hline & breadth & 15.82 & 16.00 & 16.36 & 16.27 \\
\hline
\end{tabular}

Experiment II.-From ten lots of newly hatched silk-worms 50 individuals were taken at random and intermingled. This mixture was then divided at first into two, namely, control and experimental animals. Each group was again sub-divided at the end of each age into radiated and non-radiated lots. 'Thus we have had at the fifth age ten groups, each consisting of 50 individuals. The experimental animals were exposed to radiation from 25 grams of uranium oxide, waxed between two sheets of paper measuring $465 \times 315 \mathrm{~mm}$. The results are given in the following table. 


\begin{tabular}{|c|c|c|c|c|c|c|c|c|c|c|c|}
\hline \multicolumn{2}{|c|}{ Group } & 1 & 2 & 3 & 4 & 5 & 6 & 7 & 8 & 9 & 10 \\
\hline \multicolumn{2}{|c|}{$\begin{array}{c}\text { Time of } \\
\text { irradiation }\end{array}$} & No. & $\begin{array}{l}\text { Whole } \\
\text { larval } \\
\text { period }\end{array}$ & $\begin{array}{l}\text { Ist } \\
\text { age }\end{array}$ & $\begin{array}{l}\text { 2nd } \\
\text { age }\end{array}$ & $\begin{array}{l}\text { Ist and } \\
\text { 2nd age }\end{array}$ & $\begin{array}{l}\text { 3rd } \\
\text { age }\end{array}$ & $\begin{array}{l}\text { Ist to } \\
\text { 3rd age }\end{array}$ & $\begin{array}{l}\text { 4th } \\
\text { age }\end{array}$ & $\begin{array}{l}\text { 1st to } \\
4 \text { th age }\end{array}$ & $\begin{array}{l}\text { 5th } \\
\text { age }\end{array}$ \\
\hline \multicolumn{2}{|c|}{$\begin{array}{l}\text { Duration of } \\
\text { larval period }\end{array}$} & $\begin{array}{l}22 \text { days } \\
7 \text { hours }\end{array}$ & $\mid$\begin{tabular}{|l|}
22 days \\
10 hours
\end{tabular} & Do. & Do. & Do. & Do. & Do. & Do. & Do. & $\begin{array}{l}22 \text { days } \\
7 \text { hours }\end{array}$ \\
\hline \multirow{5}{*}{ 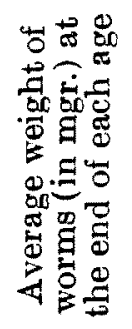 } & 1stage & 5.78 & Do. & Do. & Do. & Do. & Do. & Do. & Do. & Do. & Do. \\
\hline & 2nd age & 34.44 & 36.38 & 36.20 & 34.46 & 36.38 & 34.40 & 36.38 & 34.40 & 36.38 & 34.40 \\
\hline & $3 \mathrm{rd}$ age & 191.25 & 198.75 & 204.37 & 191.25 & 206.25 & 206.25 & 198.75 & 191.25 & 198.75 & 191.25 \\
\hline & 4th age & 1048.70 & 1047.80 & 1038.88 & 1015.10 & 1022.30 & 1043.10 & 1018.50 & 1035.10 & 1047.80 & 1048.70 \\
\hline & 5th age & 3000.00 & 3001.30 & 2992.80 & 2944.00 & 3000.00 & 3077.30 & 3040.00 & 2992.30 & 3024.00 & 3026.28 \\
\hline \multirow{2}{*}{ 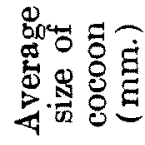 } & length & 34.32 & 35.00 & 33.70 & 34.89 & 35.39 & 34.17 & 33.73 & 34.03 & 34.00 & 34.55 \\
\hline & breadth & 16.97 & 17.23 & 17.29 & 17.50 & 17.60 & 17.23 & 16.98 & 17.15 & 17.02 & 17.09 \\
\hline \multirow{3}{*}{ 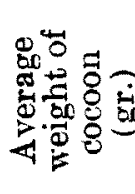 } & silk & 0.200 & 0.218 & 0.204 & 0.222 & 0.211 & 0.209 & 0.209 & 0.206 & 0.208 & 0.207 \\
\hline & pupa & 1.209 & 1.280 & 1.275 & 1.337 & 1.259 & 1.284 & 1.251 & 1.287 & 1.289 & 1.362 \\
\hline & total & 1.409 & 1.498 & 1.479 & 1.559 & 1.470 & 1.493 & 1.460 & 1.493 & 1.497 & 1.569 \\
\hline \multirow{2}{*}{ 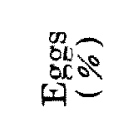 } & hatched & 87.96 & 81.22 & 92.12 & 95.00 & 87.29 & 93.20 & 91.44 & 92.83 & 89.80 & 90.40 \\
\hline & un & 12.04 & 18.78 & 7.88 & 5.00 & 12.71 & 6.80 & 8.56 & 7.16 & 10.20 & 9.60 \\
\hline
\end{tabular}

Experiment III.-Experimental animals were irradiated during pupal period with one gram of uranium oxide which was held between two cylindrically rolled sheets of paper. No difference was observable in the duration of the pupal period. But the following differences were seen in the cocoons and percentage of eggs hatched.

\begin{tabular}{|c|c|c|c|}
\hline \multicolumn{2}{|c|}{ Group } & Control & Irradiated \\
\hline \multicolumn{2}{|c|}{ Number of individuals } & 31 & 36 \\
\hline \multirow{2}{*}{$\begin{array}{l}\text { A verage weight of } \\
\text { cocoon (gr.) }\end{array}$} & silk & 0.1293 & 0.1397 \\
\hline & total & 1.1129 & 1.1142 \\
\hline Eggs & hatched & 92.54 & 90.00 \\
\hline$\%$ & undeveloped & 7.46 & 10.00 \\
\hline
\end{tabular}


Discussion.-It is quite evident that the inferiority of the group D of Experiment I was caused by lower temperature but not by longer exposue to radiation. All the other results show that uranium radiation increases the weight of the silk-worms but not always accelerates their development. Remarkably enough, the cocoons produced by those which were irradiated at the fifth and second age are heavier than the others. This fact seems to us partly due to the difference of susceptibility of the worms to radiation at each age, and partly due to duration of irradiation. As is well known, the silk-worms pass through the second age faster than the other. Consequently, it is evident that they are exceedingly active and therefore greatly susceptible to radiation at this age. The fifth age is also a period of great activity though it is the longest of all. And it would be superfluous to say that there exists marked susceptibility to radiation at this fifth age. As regards the efficient duration of irradiation, the fact that comparatively lighter cocoons are obtained by those which were irradiated during the whole larval period seems to point to the conclusion that such a duration is too long to produce the best result. 